\title{
Erratum to: What is the Effect of Critical Surface Tension of $\mathrm{PbSO}_{3}$ Thin Film?
}

\section{AFŞIN KARIPER}

DOI: $10.1007 / \mathrm{s} 11661-014-2455-2$

(C) The Minerals, Metals \& Materials Society and ASM International 2014

\section{Erratum to: METALLURGICAL AND MATERIALS TRANSACTIONS A DOI: 10.1007/s11661-014-2387-x}

IN the original article, the figure captions and the y-axes for Figures 4, 5, and 6 should read Critical Surface Tension. Following are the corrected figures:

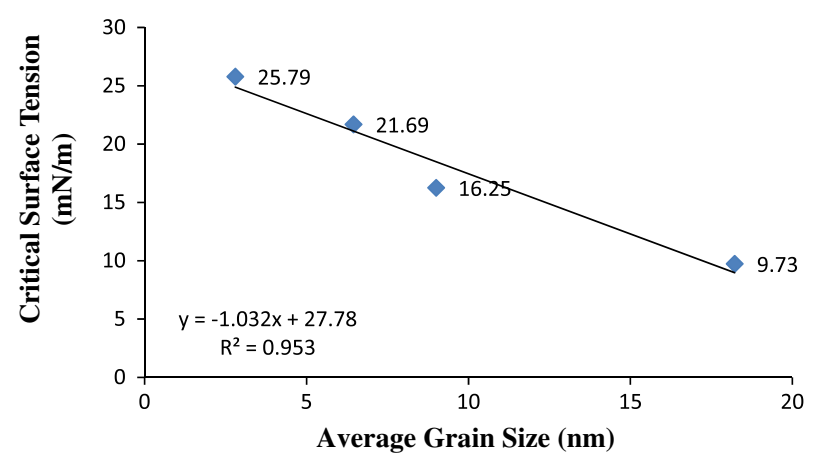

Fig. 4 - Critical surface tension of $\mathrm{PbSO}_{3}$ thin films with average grain size.

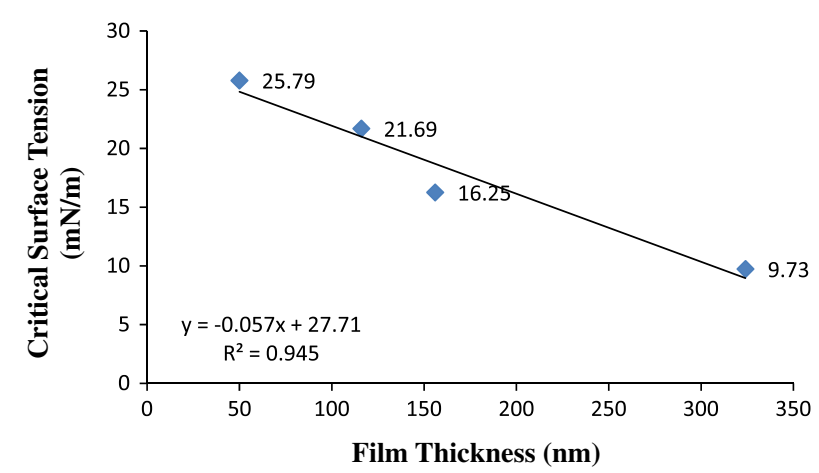

Fig. 5- Critical surface tension of $\mathrm{PbSO}_{3}$ thin films with the film thickness.

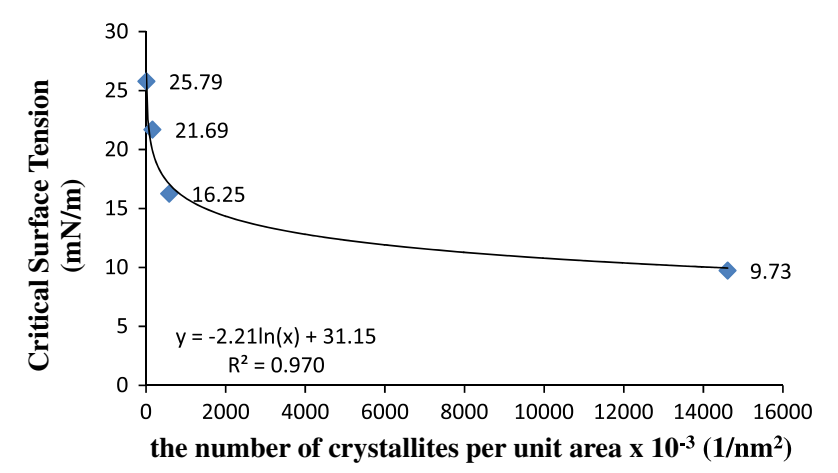

Fig. 6 - Critical surface tension of $\mathrm{PbSO}_{3}$ thin films with the no. of crystallites per unit area.
I. AFŞIN KARIPER, Researcher Doctor, is with the Faculty of Education, Erciyes University, 38039 Kayseri, Turkey. Contact e-mail: akariper@gmail.com

The online version of the original article can be found under doi: 10.1007/s11661-014-2387-x.

Article published online July 9, 2014 